\title{
Biofabrication of bundles of poly(lactic acid)-collagen blends mimicking the fascicles of the human Achille tendon
}

\author{
Alberto Sensini ${ }^{1}$, Chiara Gualandi ${ }^{2}{ }^{*}$, Luca Cristofolini ${ }^{1,3}$, Gianluca Tozzi ${ }^{4}$, \\ Manuela Dicarlo ${ }^{5}$, Gabriella Teti ${ }^{6}$, Monica Mattioli-Belmonte ${ }^{5}$ and Maria \\ Letizia Focarete ${ }^{2,3}$
}

${ }^{1}$ Department of Industrial Engineering, Alma Mater Studiorum - University of Bologna, 40131 Bologna, Italy

${ }^{2}$ Department of Chemistry "G. Ciamician" and National Consortium of Materials Science and Technology (INSTM, Bologna RU), Alma Mater Studiorum - University of Bologna, 40126 Bologna, Italy

${ }^{3}$ Health Sciences and Technologies - Interdepartmental Center for Industrial Research (HST-ICIR), Alma Mater Studiorum - University of Bologna, 40064 Ozzano dell’Emilia, Bologna, Italy

${ }^{4}$ School of Engineering, University of Portsmouth, Portsmouth PO1 3DJ, United Kingdom

${ }^{5}$ Department of Clinical and Molecular Sciences, Polytechnic University of Marche, School of Medicine, 60126 Ancona, Italy

${ }^{6}$ Department of Biomedical and Neuromotor Sciences, Alma Mater Studiorum - University of Bologna, 40126 Bologna, Italy

Corresponding Author: Chiara Gualandi, PhD.E-mail: c.gualandi@unibo.it 


\begin{abstract}
Electrospinning is a promising technique for the production of scaffolds aimed at the regeneration of soft tissues. The aim of this work was to develop electrospun bundles mimicking the architecture and mechanical properties of the fascicles of the human Achille tendon. Two different blends of poly(L-lactic acid) (PLLA) and collagen (Coll) were tested, PLLA/Coll-75/25 and PLLA/Coll50/50, and compared with bundles of pure PLLA. First, a complete physico-chemical characterization was performed on non-woven mats made of randomly arranged fibers. The presence of collagen in the fibers was assessed by thermogravimetric analysis, differential scanning calorimetry and water contact angle measurements. The collagen release in phosphate buffer solution (PBS) was evaluated for 14 days: results showed that collagen loss was about 50\% for PLLA/Coll-75/25 and 70\% for PLLA/Coll-50/50. In the bundles, the individual fibers had a diameter of $0.48 \pm 0.14 \mu \mathrm{m}$ (PLLA), $0.31 \pm 0.09 \mu \mathrm{m}$ (PLLA/Coll-75/25), 0.33 $\pm 0.08 \mu \mathrm{m}$ (PLLA/Coll50/50), whereas bundle diameter was in the range 300-500 $\mu \mathrm{m}$ for all samples. Monotonic tensile tests were performed to measure the mechanical properties of PLLA bundles (as-spun) and of PLLA/Coll-75/25 and PLLA/Coll-50/50 bundles (as-spun, and after 48 hour, 7 days and 14 days in PBS). The most promising material was the PLLA/Coll-75/25 blend with a Young modulus of

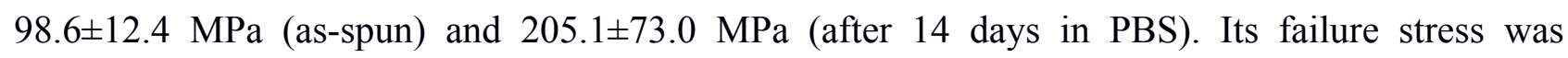
14.2 $\pm 0.7 \mathrm{MPa}$ (as-spun) and 6.8 $\pm 0.6 \mathrm{MPa}$ (after 14 days in PBS). Pure PLLA withstood slightly lower stress than the PLLA/Coll-75/25 while PLLA/Coll-50/50 had a brittle behavior. Humanderived tenocytes were used for cellular tests. A good cell adhesion and viability after 14 day culture was observed. This study has therefore demonstrated the feasibility of fabricating electrospun bundles with multiscale structure and mechanical properties similar to the human tendon.
\end{abstract}

Keywords: human Achille tendon, electrospinning, bundle, poly(lactic acid), collagen, tissue engineering, tenocytes.

\title{
1. Introduction
}

The reconstruction of the tendon tissue is a current problem in medicine and orthopedic surgery. Over 30 million human tendon-related procedures take place annually worldwide [1]. However, due to the anatomical and physiological complexity of the hierarchical structure of this tissue, it is very difficult to obtain satisfactory results [2-4]. Often, the formation of scar tissue generates morphological discontinuities which impair the mechanical properties and the proper work of the 
tendon [5]. Moreover, since tendon responds to mechanical forces by adapting its metabolism and its mechanical properties [6], its immobilization for long periods decreases its mass and reduces its stiffness and strength [7]. Surgical intervention is frequently considered in serious injuries and when damage is extensive tendon grafts may be required [8]. The grafts can be i) prosthetic devices made of synthetic materials, ii) allografts, iii) autografts and iv) resorbable devices. The choice of the most suitable option encompasses considerations of the type and site of injury and of the patient but, in a way, all the options above present some drawbacks. For instance prosthetic devices, besides developing inflammatory process, can encounter mechanical damage over time [9]. Autografts are better immunologically suitable, but their success is associated to morbidity of the donor site [10-15]. Alternatively, with autografts the risk of rejection exists [16-19]. Tendon reconstruction through tissue engineering is an additional option that encompasses the use of a biocompatible and bioresorbable scaffold capable of promoting tissue healing and of withstanding mechanical stresses. The design of a scaffold for tendon reconstruction must take into account the complex hierarchical structure of native tendon which is constituted by Collagen Type I (Coll) filaments aggregated in fascicles, with increasing diameters, orientated in the directions of applied loads $[20,21]$.

One promising technique for the production of scaffolds for tendon tissue is electrospinning. Thanks to its ability to produce filaments of both natural and synthetic polymers with nano- and micrometric diameters and oriented in specific directions, electrospinning grants the potential of producing scaffolds morphologically very similar to the hierarchical structure of the tendon collagen fascicles. Several technical approaches have been developed for producing electrospun bundles of highly aligned fibers [22-24] that have been proposed for tendon tissue engineering [23, 25-27]. Bosworth et al., in particular, developed electrospun bundles of poly( $\varepsilon$-caprolactone), they carried out in vitro cell culture under dynamic tensile loading [27] and assessed the in vivo performance of the bundles [26], gaining encouraging results. Recently, Zhang et al. demonstrated that the unidirectional alignment of electroscope fibres helps enabling tenogenic differentiation of human-induced pluripotent stem cells in vitro and in vivo [28]. Mouthuy et al. developed a robust and automated method to manufacture continuous electrospun filaments that can be stretched and used to create multifilament yarns that imitate the hierarchical architecture of tendons and ligaments [23]. Besides morphological features of the scaffold, it is well-established that chemical properties are also extremely important in ensuring cell adhesion and proliferation. Because of their inherent properties of biological recognition, natural polymers have therefore been proposed in combination with synthetic polymers for tendon reconstruction: for instance poly(L-lactide-co- $\varepsilon$-caprolactone) copolymer has been blended with either collagen [29] or silk [30] and chitosan and gelatin have 
been used in combination with poly(L-lactic acid) (PLLA) [28]. While blends of collagen and PLLA have been investigated in the past [31-34] they have never been manufactured to produce bundles for tendon reconstruction. Moreover, the effect of the amount of the natural component on the mechanical properties of the bundle and on cell behaviour, as well the stability of bundle composition under physiological condition have never been deeply investigated.

The aim of this study was to design, manufacture and characterize bioresorbable electrospun bundles made of highly aligned fibers of PLLA-collagen blends, to mimic the morphology and mechanical properties of the bundles composing the human Achilles tendon $(300-500 \mu \mathrm{m}$ in diameter). The two polymers were selected in order to seek an optimal compromise in terms of biocompatibility, stiffness, hydrolytic degradation and toughness. Bundles of PLLA containing different amounts of collagen have been prepared and characterized to determine the effect of collagen on scaffold wettability, thermal and mechanical properties. The compositional stability of the scaffold and its mechanical performances have been evaluated over 14 days. Human tenocytes were cultured over the same time range on the bundles and cell morphology was assessed by Scanning and Transmission Electron microscopy.

\section{Materials and Methods}

In a first phase, flat mats were prepared to allow physico-chemical characterization of the material, bundles were then prepared to assess the mechanical properties and to perform cell culture experiments.

\subsection{Materials}

Acid soluble collagen type I (Coll), extracted from bovine skin was kindly provided by Kensey Nash Corporation d/b/a DSM Biomedical (Exton, USA). Poly-L-lactic acid (PLLA) (Lacea H.100$\mathrm{E}, \mathrm{M}_{\mathrm{w}}=8.4 \times 10^{4} \mathrm{~g} / \mathrm{mol}$, PDI = 1.7) was purchased from Mitsui Fine Chemicals (Dusseldorf, Germany). 2,2,2-Trifluoroethanol (TFE), 1,1,1,3,3,3-Hexafluoro-2-propanol (HFIP), Dichloromethane (DCM) and Dimethylformamide (DMF) were purchased from Sigma-Aldrich and used as received. The following polymeric solutions were used: (i) PLLA samples were produced from a 13\% (w/v) solution of PLLA dissolved in DCM:DMF=65:35 (v/v); (ii) PLLA/Coll-75/25 $(\mathrm{w} / \mathrm{w})$ samples were prepared from a $15 \%(\mathrm{w} / \mathrm{v})$ solution of PLLA and Coll dissolved in TFE:HFIP=50:50 (v/v) (1.125 g of PLLA and 0.375 $\mathrm{g}$ of Coll were dissolved in $10 \mathrm{~mL})$; 
PLLA/Coll-50/50 (w/w) samples were prepared from a 15\% (w/v) solution of PLLA and Coll dissolved in TFE:HFIP=50:50 (v/v) (0.75 g of PLLA and 0.75 $\mathrm{g}$ of Coll were dissolved in $10 \mathrm{~mL})$.

\subsection{Electrospinning and imaging}

The home-made electrospinning apparatus consisted of a high-voltage power supply (Spellman SL 50 P 10/CE/230), a syringe pump (KD Scientific 200 series), a glass syringe containing the polymer solution and connected to a stainless-steel blunt-ended needle through a Teflon tube. Electrospinning was performed at room temperature (RT) and relative humidity 40-50\%. PLLA solution was electrospun by applying the following processing conditions: applied voltage $=18 \mathrm{kV}$, feed rate $=1.2 \mathrm{~mL} / \mathrm{h}$, needle inner diameter $=0.84 \mathrm{~mm}$. PLLA/Coll solutions were electrospun by applying the following processing conditions: applied voltage $=22 \mathrm{kV}$, feed rate $=0.5 \mathrm{~mL} / \mathrm{h}$, needle inner diameter $=0.51 \mathrm{~mm}$.

The grounded collector was positioned $200 \mathrm{~mm}$ away from the tip of the needle. The non-woven mats made of randomly arranged fibers were electrospun on an aluminium flat plate (100 mm x 100 $\mathrm{mm}$ ). A high-speed rotating collector (length $=120 \mathrm{~mm}$, diameter $=50 \mathrm{~mm}, 6000 \mathrm{rpm}$, peripheral speed $=16.2 \mathrm{~m} / \mathrm{s}$ ) was used to produce mats made of fibers preferentially aligned in the direction of drum rotation as previously described $[35,36]$ (figure 1(A)). The central part of the sleeve (about 75 $\mathrm{mm}$ long) was manually rolled up transversely to the length of the roller, from end to end (figure 1(B)). To remove it from the collector, the rolled-up scaffold was incised axially with a cutter (figure 1(C)). Thus, the final bundle was as long as the circumference of the rotating collector (approximately $150 \mathrm{~mm}$ ), and was made of fibers predominantly aligned axially (figure 1(D)).

Scanning Electron Microscopy (SEM) observations were carried out using a Philips 515 SEM at an accelerating voltage of $15 \mathrm{kV}$, on samples sputter-coated with gold both of flat mats and bundles. The distribution of fiber diameters (average and standard deviation) was measured on the SEM images of about 200 fibers, by means of an acquisition and image analysis software (EDAX Genesis). The one-way ANOVA was used to test the statistical significance of the differences between averages.

The diameter of each bundle depended on the amount of fibres deposited in the central part of the collector, that in turn was affected by polymeric solution concentration, flow rate and jet deposition diameter. For each blend, the deposition time was optimized to produce bundles with a diameter of 300-500 $\mu \mathrm{m}$ (figures $1(\mathrm{E})$ and $1(\mathrm{~F})$ ).

In addition, to investigate the three-dimensional structure high-resolution images of one bundle was acquired with a micro-computed tomography scanner (micro-CT) (ZEISS Xradia 520 Versa) (figure $1(\mathrm{G})$ ) with the following settings: $40 \mathrm{kV} / 3 \mathrm{~W}$ Power, $149 \mu \mathrm{A}$ tube current, 10-12 seconds exposure time. Images were collected at rotational steps of $0.09-0.11$ over $360^{\circ}$, for a scanning time of $10-15$ 
hours. The reconstructed micro-CT images had an isotropic voxel size of $0.4 \mu \mathrm{m}$. To quantify directionality and scatter, the scans were analysed with ImageJ [37], using a dedicated plugin called Directionality [38-39]. Directionality histogram reports the amount of fibers as a function of the fiber orientation. The fiber alignment followed a gaussian distribution (goodness $>0.90$ ) with a narrow scatter (standard deviation $<15^{\circ}$, figure $1(\mathrm{~F})$ ). The $3 \mathrm{D}$ reconstruction video of the bundle is available as Supporting Information.

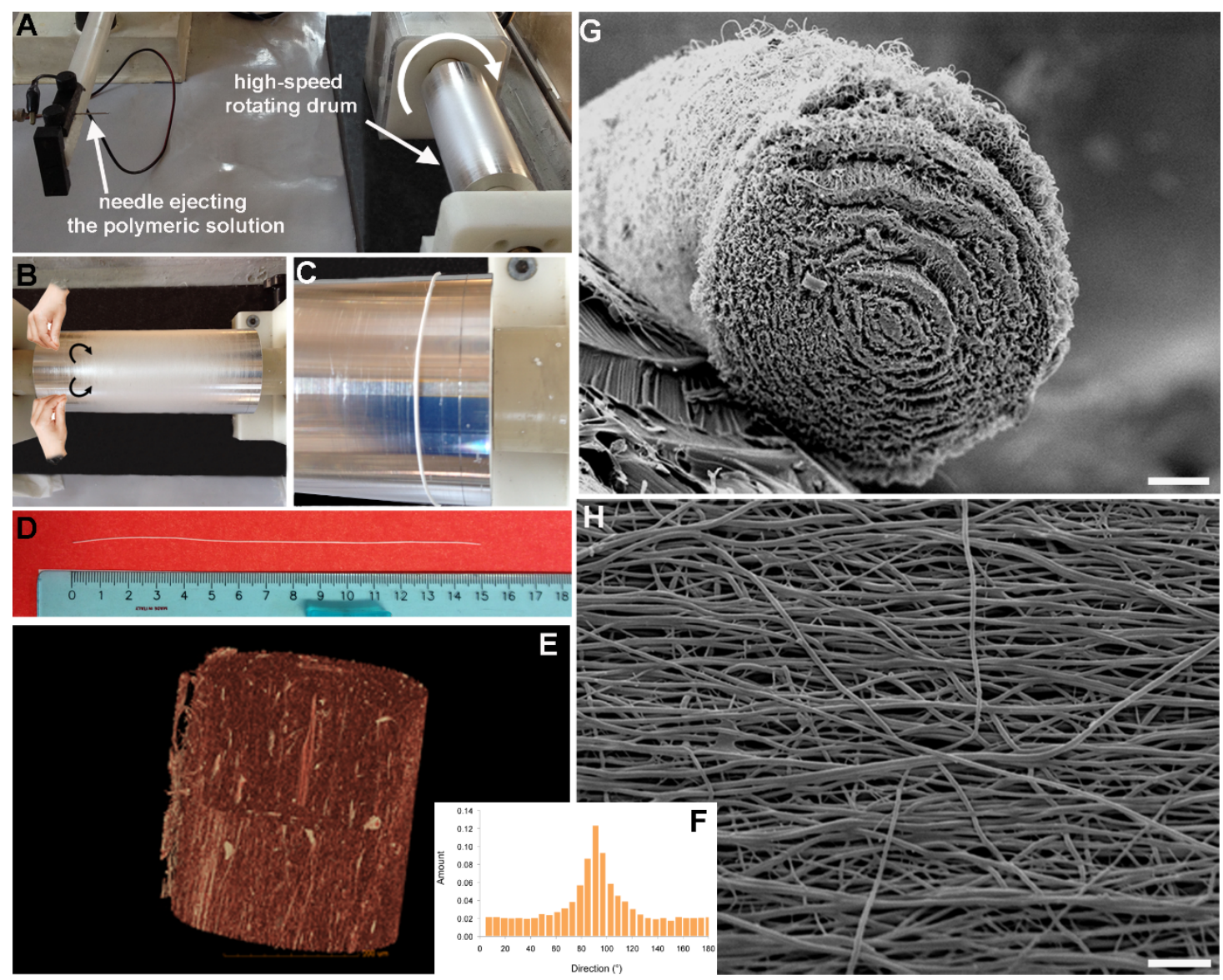

Figure 1. Procedure for the fabrication of the bundles: polymeric fibers were collected on a highspeed rotating drum (A) the mat made of aligned fibers was manually rolled up (B and C) to produce a bundle (D). The three-dimensional organization from the micro-CT images is reported as an example for a typical PLLA/Coll-50/50 specimen $(\mathrm{E}$, scale bar $=200 \mu \mathrm{m})$. The Directionality histogram is also reported for the same specimen ( $\mathrm{F}$, in degrees). The real histogram values are used for the summation, not the gaussian fit. SEM images of a bundle are reported for a section $(\mathrm{G}$, scale bar $=50 \mu \mathrm{m})$ and for the external surface $(\mathrm{H}$, scale bar $=5 \mu \mathrm{m})$.

\subsection{Release of collagen from the electrospun mats}

Specimens of non-woven mats made of randomly arranged fibers (about $25 \mathrm{mg}$ ) were dried over $\mathrm{P}_{2} \mathrm{O}_{5}$ under vacuum at $\mathrm{RT}$ and weighed to obtain the sample initial mass. The specimens were individually immersed in $3 \mathrm{~mL}$ of PBS $(0.1 \mathrm{M}$, pH $=7.4)$ with sodium azide (Sigma-Aldrich) and 
incubated in a SW22 Julabo water bath at $37^{\circ} \mathrm{C}$ with shaking at $80 \mathrm{rpm}$. At different time intervals, triplicate specimens for each sample were recovered from the bath, gently washed with deionized water and dried over $\mathrm{P}_{2} \mathrm{O}_{5}$ under vacuum.

The amount of collagen released in the PBS (Collagen Loss \%) was determined using Biuret assay [40]. The Biuret reagent was prepared by dissolving $0.375 \mathrm{~g}$ of copper sulphate (Sigma-Aldrich) and $1.69 \mathrm{~g}$ of sodium tartrate hemihydrate (Sigma-Aldrich) in $100 \mathrm{~mL}$ distilled water. Subsequently, $100 \mathrm{~mL}$ of $10.5 \%(\mathrm{w} / \mathrm{v}) \mathrm{NaOH}$ was added to the solution. The resulting solution was then diluted up to $250 \mathrm{~mL}$ and stored at $2-8{ }^{\circ} \mathrm{C} .0 .5 \mathrm{~mL}$ of the retrieved PBS which previously contained the mat specimen was mixed with $2.25 \mathrm{~mL}$ of Biuret assay solution and kept at RT for 10 min. UV absorbance at $545 \mathrm{~nm}$ was measured with a Cary 1E (Varian) spectrophotometer, and converted to collagen concentration through a calibration curve obtained by measuring the absorbance of collagen standard solutions. Collagen Loss \% was calculated:

Collagen Loss $\%=\frac{\mathrm{m}_{\text {Coll }}}{\mathrm{m}_{\mathrm{in}} \times \mathrm{w}_{\text {Coll }}} \times 100$

Where $m_{\text {Coll }}$ is the mass of Collagen released in PBS determined by Biuret assay, $m_{i n}$ is the initial dry sample weight and $\mathrm{w}_{\text {Coll }}$ is the Collagen weight fraction in the flat mats (i.e. $\mathrm{w}_{\text {Coll }}=0.25$ for PLLA/Coll-75/25 and $\mathrm{w}_{\text {Coll }}=0.5$ for PLLA/Coll-50/50). The same analysis was also carried out on PBS medium containing PLLA mats, demonstrating that substances interfering with the Biuret method were absent.

In parallel, the Collagen Loss \% was also evaluated gravimetrically by comparing the sample dry weight remaining at a specific time with the initial sample weight (Equation 2) and by assuming that the weight loss was only ascribable to collagen dissolution. This assumption was supported by the fact that PLLA mat incubated in PBS did not show any weight loss in the time range investigated (up to 14 days).

Collagen Loss $\%=\frac{m_{\text {in }}-m_{\text {fin }}}{m_{\text {in }} \times w_{\text {Coll }}} \times 100$

Where $m_{\text {in }}$ is the initial dry sample weight, $m_{\text {fin }}$ is the dry sample weight after PBS immersion and $\mathrm{w}_{\text {Coll }}$ is the Collagen weight fraction in the flat mats sample (i.e. $\mathrm{w}_{\text {Coll }}=0.25$ for PLLA/Coll-75/25 and $\mathrm{w}_{\text {Coll }}=0.5$ for PLLA/Coll-50/50).

\subsection{Physico-chemical characterization techniques}

Thermogravimetric analysis (TGA) were performed with a TA Instruments TGA2950 analyzer from RT to $600{ }^{\circ} \mathrm{C}$ (heating rate $10^{\circ} \mathrm{C} / \mathrm{min}$, nitrogen gas).

Differential Scanning Calorimetry (DSC) measurements were carried out using a TA Instruments Q100 DSC equipped with the Liquid Nitrogen Cooling System (LNCS) accessory. DSC scans were 
performed in helium atmosphere from -60 to $190{ }^{\circ} \mathrm{C}$. The heating rate was $20{ }^{\circ} \mathrm{C} / \mathrm{min}$ and the cooling rate was $10{ }^{\circ} \mathrm{C} / \mathrm{min}$.

The static water contact angle (WCA) was measured under ambient conditions with a KSV CAM 101 instrument. Milli-Q water was used for measurements. The side profiles of water drops laying on the surface of non-woven mats made of randomly arranged fibers were recorded in a time range 0-30 s. At least six drops were observed for each mat.

\subsection{Mechanical characterization of the bundles}

Stress-strain measurements were carried out with a material testing machine (Mod. 4465, Instron, Canton, MA) on electrospun bundles of the three compositions. In order to evaluate the variation of mechanical properties in relation to collagen loss, bundles of PLLA/Coll-75/25 and PLLA/Coll50/50 were also immersed in $\mathrm{PBS}$ at $37^{\circ} \mathrm{C}$ for 48 hours, 7 days and 14 days. After these time intervals, the bundles were retrieved from PBS and dried before mechanical testing. Six specimens were tested for each composition and each type of ageing. To measure the diameter of each bundle, a polarized light optical microscope (Axioskop Zeiss,) equipped with a camera (AxioCam MRc Zeiss) was used (average of 5 measurements). The section was measured (average of 5 measurements) immediately after preparation of the bundles, and also after permanence in PBS (where applicable).

'Ad hoc' designed capstan grips were used to limit the stress concentrations at sample ends. The gauge length was $20 \mathrm{~mm}$. The actuator speed was $5 \mathrm{~mm} / \mathrm{min}$. Load-displacement curves were converted to stress-strain curves using the cross-section area measured in the dry specimens asspun. The following indicators were considered: Young modulus, yield stress, failure stress, failure strain, and work to yield and failure. The stress-strain curves were analysed as described in figure 2.

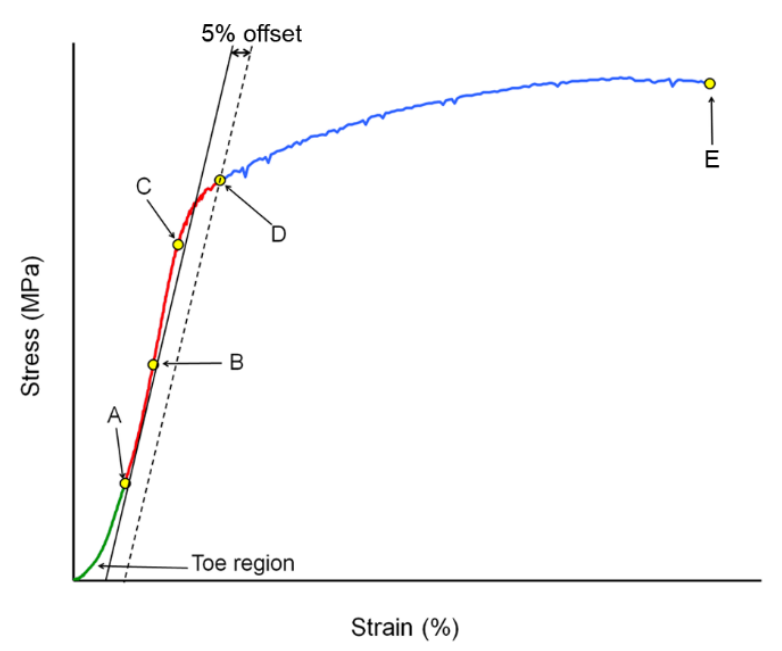


Figure 2. Sketch of the method used to analyse the stress-strain curves. The initial toe region was disregarded; the failure stress (E) was identified as the highest stress in the entire curve; the starting point of the linear region (A) was univocally identified as $20 \%$ of failure stress; an initial guess for the yield strain was visually identified $(\mathrm{C})$; the initial linear regression (solid line) was applied to the first $50 \%$ of the linear region, between points A and B (which was half-way between A and C); a second line parallel to the initial regression was drawn, with an offset of 5\% strain (dashed line); the limit of proportionality was defined with the $0.5 \%$-strain offset criterion as the intersection (D) between the latter line and the stress-strain curve; the Young modulus was calculated as the slope of a new regression line between $\mathrm{A}$ and $\mathrm{D}$. The work to yield and to failure were calculated as the integrals under the curves (with the method of trapezoids).

The significance of differences between bundle compositions was assessed with the one-way ANOVA; the effect of PBS immersion on the two blends was assessed with the two-way ANOVA.

\subsection{Biological assessment}

\section{Cell Isolation}

Human tenocytes were isolated from anterior cruciate ligament of healthy subjects undergoing surgery for orthopaedic trauma (mean age 60 years). In accordance with the Local Ethical Committee guidelines and with the 1964 Helsinki declaration an informed consent was obtained from all individual participants included in the study. Briefly, ligament explants were aseptically rinsed three times with Dulbecco's Phosphate-Buffered Saline (D-PBS) lacking in $\mathrm{Ca}^{2+}$ and $\mathrm{Mg}^{2+}$, then cut into small pieces and incubated with $1 \mathrm{mg} / \mathrm{mL}$ type I collagenase (Collagenase NB 4G Proved Grade, Serva Electrophoresis GmbH) in Dulbecco's modified Eagle's medium (DMEM; Sigma-Aldrich, Milan, Italy) supplemented with $2 \%$ foetal bovine serum (FBS) and 1\% antibiotics (penicillin-streptomycin; Gibco-Life Technologies, Milan, Italy) for approximately 18 hours at $37^{\circ} \mathrm{C}$ in controlled atmosphere.

After digestion, the suspension was passed through a sterile cell strainer (70 $\mu \mathrm{m}$ in diameter) to remove debris and the filtrate centrifuged at $1200 \mathrm{rpm}$ for $10 \mathrm{~min}$. The cell pellet was then resuspended in DMEM supplemented with 10\% FBS and 1\% antibiotics, and placed in sterile vented cell culture flasks. The medium was changed twice a week. Confluent cells were detached with $0.25 \%$ trypsin in $1 \mathrm{mM}$ ethylenediaminetetraacetic acid (EDTA) (Gibco-Life Technologies) and split $1: 2$.

Cell characterization 
Tenocytes at the $3^{\text {rd }}$ passage were seeded in chamber-slides (NuncTM, Rochester, NY) at a density of $5 \times 10^{3}$ cells $/ \mathrm{cm}^{2}$. At confluence, cells were fixed in $4 \%$ paraformaldehyde in PBS for 15 min at RT, permeabilized using $0.1 \%$ Triton-X-100 in D-PBS for 15 mins at RT, and then incubated with anti-fibronectin (dil. 1:600; clone IST-4, Sigma Aldrich), anti-collagen Type I (dil. 1:1000; clone COL-1, Abcam Cambridge, UK), anti-collagen Type III (dil. 1:100; clone Col-29, Abcam) or antivimentin (ready to use, Clone V9, Dako Cytomation, Milan, Italy) mouse monoclonal antibodies. Cells were incubated overnight at $4^{\circ} \mathrm{C}$ with primary antibodies and then washed in D-PBS. The immuno-complexes were visualized using the streptavidin-biotin peroxidase technique (Envision peroxidase kit, Dako). After the incubation with 0.05\% 3, 3'-diaminobenzidine (Sigma-Aldrich) in 0.05 M Tris buffer, $\mathrm{pH} 7.6$ with $0.01 \%$ hydrogen peroxide, cells were counterstained with Mayer's haematoxylin (BioOptica, Milan, Italy), dehydrated in ethanol and coverslipped with Eukitt mounting medium (Electron Microscopy Sciences, PA, USA). For negative controls, the primary antibody was replaced with non-immune serum. The immunohistochemical expression of the before mentioned antigens was evaluated under a Nikon Eclipse E600 light microscope (Nikon, Milan, Italy). Images were captured with a Nikon DSVil digital camera (Nikon Instruments) and NIS Elements BR 3.22 imaging software (Nikon Instruments) was used. Stained cells were counted in at least 10 fields per sample (field's area: $0.7 \mathrm{~mm}^{2}$, magnification: $400 \mathrm{X}$ ) and quantified as a percentage of the total counted cells. The fields were randomly selected evaluating the most positive, moderate and less positive areas. Average \pm standard deviation (SD) was considered for each value.

\section{Cell Cultures}

Before seeding, PLLA/Coll-75/25 and PLLA/Coll-50/50 bundles were sterilized with 70\% ethanol for 30 min, washed twice in D-PBS, and then incubated with DMEM supplemented with 10\% FBS and $1 \%$ penicillin-streptomycin $(100 \mathrm{U} / \mathrm{mL})$ at $37^{\circ} \mathrm{C}$. After one hour, the bundles were cut into 1$\mathrm{cm}$ pieces and placed in 24-well polystyrene plates (Corning ${ }^{\circledR}$ ultra-low attachment) and fixed with CellCrown $^{\mathrm{TM}}$ (Scaffdex, Tampere, Finland). Tenocytes were detached from culture flasks using $0.25 \%$ trypsin in $1 \mathrm{mM}$ EDTA and seeded on the samples at a density of $1 \times 10^{5}$ cells $/$ sample in a volume of $50 \mu \mathrm{L}$. After one hour incubation at $37^{\circ} \mathrm{C}$, necessary to allow cell adhesion and prevent sliding off and falling in the wells, $1 \mathrm{~mL}$ of DMEM was added in each well, and samples were further cultured for 7 and 14 days. Medium was changed twice a week.

Scanning Electron Microscopy (SEM)

For SEM analysis, the cell-material constructs were fixed in $2 \% \mathrm{v} / \mathrm{v}$ glutaraldehyde in $0.1 \mathrm{M}$ cacodylate buffer $\left(\mathrm{pH} \mathrm{7.4)}\right.$ ) for $1 \mathrm{~h}$ at $4{ }^{\circ} \mathrm{C}$, post-fixed in $1 \% \mathrm{v} / \mathrm{v}$ osmium tetroxide for $1 \mathrm{~h}$ at $4^{\circ} \mathrm{C}$, dehydrated for $15 \mathrm{~min}$ at $4{ }^{\circ} \mathrm{C}$ in a series of increasing ethanol concentrations (from $25 \%$ to absolute 
ethanol), critical point dried using CPD 010 Balzers Instruments (FL-9496 Balzers, Liechtenstein) according to the manufacturer's instructions, mounted on aluminium stubs and gold-sputtered (Edwards Sputter Coater B150S). Samples were observed with a Philips XL 20 SEM (FEI Italia SRL, Milan, Italy) using the secondary electron detector.

Transmission Electron Microscopy (TEM)

Samples were fixed in $2.5 \%$ glutaraldehyde in $0.1 \mathrm{M}$ cacodylate buffer for $2 \mathrm{~h}$ at $4^{\circ} \mathrm{C}$ and post-fixed in $1 \%$. Osmium tetroxide in $0.1 \mathrm{M}$ cacodylate buffer for $30 \mathrm{~min}$ at RT. Samples were dehydrated in graded ethanol and finally infiltrated and embedded in RL London White (Fluka, Sigma Aldrich, St. Louis, Missouri, USA). $100 \mathrm{~nm}$ ultra-thin sections were cut using a Diatome (Diatome, Hatfield, PA, USA) diamond knife on a NOVA LKB Ultratome. Sections were picked up on nickel grids and stained with alcoholic uranyl acetate and Reynold's lead citrate. Ultrastructural examination was performed using the Philips CM10 Transmission Microscope (FEI Company, Eindhoven, The Netherlands). Images were recorded by Megaview III digital camera (FEI Company, Eindhoven, The Netherlands).

\section{Results}

\subsection{Morphology of the electrospun mats}

Electrospun mats made of randomly oriented continuous fibers were produced by collecting fibers on an aluminium plate target (figure 3). PLLA bead-free fibers with diameters of $(0.48 \pm 0.14) \mu \mathrm{m}$ were obtained as previously reported [41-43] by dissolving the polymer in a mixture of DCM (to dissolve the polymer) and DMF (to improve the electrical properties of the solution). PLLA/Coll$75 / 25$ fibers had diameters of $(0.31 \pm 0.09) \mu \mathrm{m}$ and PLLA/Coll-50/50 fibers had diameters of $(0.33$ $\pm 0.08) \mu \mathrm{m}$ (figure 3).

The behaviour of a representative water drop for each sample is reported in figure 3(E). PLLA mat displayed a WCA of $110^{\circ} \pm 6^{\circ}$ that remained constant during the measurement. Conversely, for PLLA/Coll samples the WCA values significantly decreased with time: the water drop was completely absorbed after 30 and $10 \mathrm{sec}$ by PLLA/Coll-75/25 and PLLA/Coll-50/50 mat, respectively. 

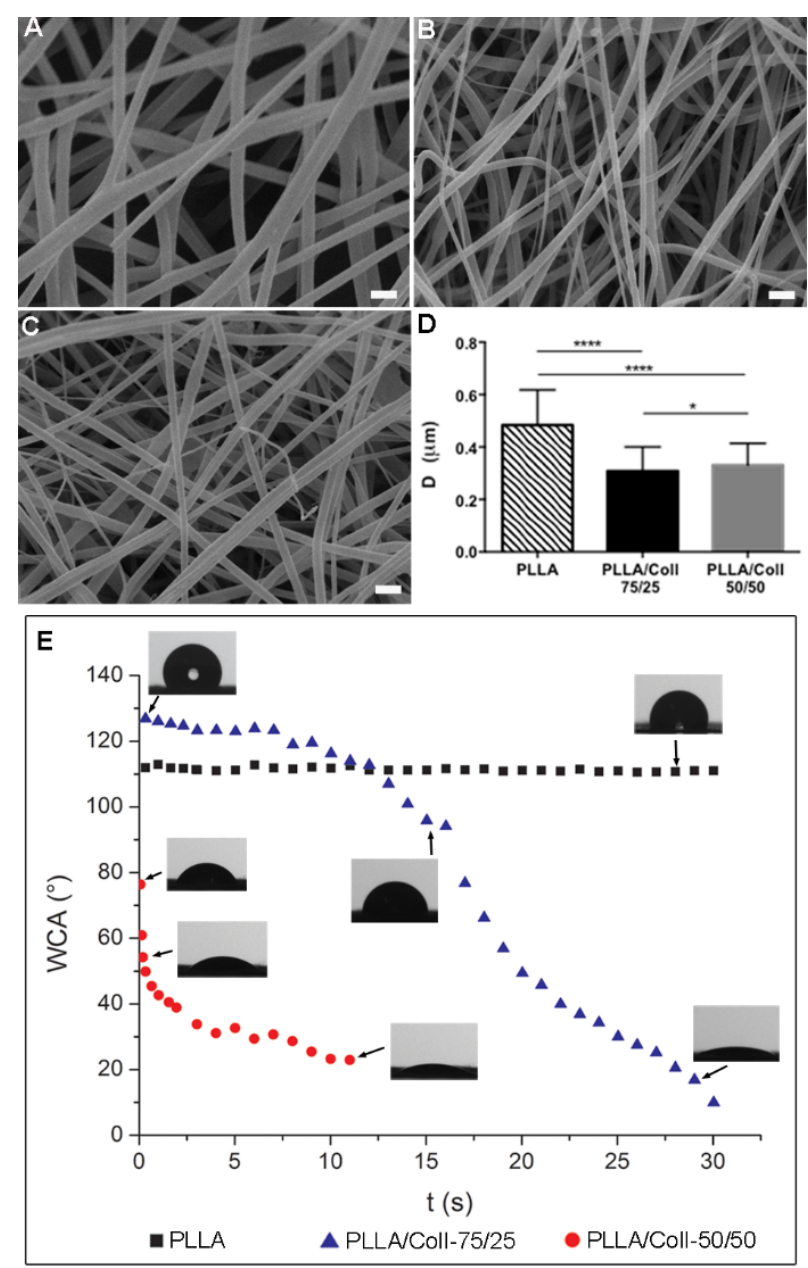

Figure 3. Representative SEM micrographs of PLLA (A), PLLA/Coll-75/25 (B) and PLLA/Coll50/50 (C) non-woven mats of randomly arranged fibers. Scale bar $=1 \mu \mathrm{m}$. The diameter (average and standard deviation) of the fibers is plotted for the three compositions (D), together with statistical significance of post-hoc comparisons (Tuckey multiple comparisons, * $\mathrm{P} \leq 0.05$, ** $\mathrm{P} \leq$ $0.01, * * * \mathrm{P} \leq 0.001, * * * * \mathrm{P} \leq 0.0001$ ). (E) WCA as a function of time of a representative drop for each electrospun mat.

\subsection{Thermal characterization of the electrospun mats}

TGA curves of electrospun mats are reported in figure 4(A). For sake of comparison, TGA of collagen powder is also shown. PLLA sample started losing weight above $250^{\circ} \mathrm{C}$ and degraded in a single-step process that leaded to an almost negligible residue $(4 \%)$ above $350^{\circ} \mathrm{C}$. Thermal degradation of collagen powder proceeded via a multistep process that started at RT with a residual weight of about $27 \%$ at $600^{\circ} \mathrm{C}$. Collagen weight loss at low temperature $\left(\mathrm{RT}-150^{\circ} \mathrm{C}\right)$ has been attributed to the removal of bound water [44, 45]. Similarly, to collagen powder, PLLA/Coll samples displayed an initial weight loss in the range $\mathrm{RT}-150^{\circ} \mathrm{C}$, ascribable to water evaporation from the Coll component. Subsequently, the samples showed a weight decrement in the range 200- 
$500^{\circ} \mathrm{C}$, due to the concomitant degradation of Coll and PLLA fractions, and weight residues at $600^{\circ} \mathrm{C}$ of $18 \%$ and $10 \%$ for PLLA/Coll-50/50 and PLLA/Coll-75/25, respectively. The residual weights at $600^{\circ} \mathrm{C}$ of blends were in line with the theoretical ones, the latter being calculated by considering the feed of PLLA and Coll in the starting polymeric solutions. Indeed, the theoretical residual weight values - calculated by taking into account the weight residues of pure components of PLLA/Coll-50/50 and PLLA/Coll-75/25 are 15.5\% and 9.75\%, respectively, which are close to the experimental ones, within the accuracy of TGA quantification.

The DSC curve of collagen powder showed a broad and intense endothermic peak in the range 0$150^{\circ} \mathrm{C}$ in the first heating scan (figure 4(B)), due to the evaporation of water [44], whereas no appreciable thermal transitions where observed in the second heating scan (figure 4(C)). The first heating scan of PLLA showed a glass transition $\left(\mathrm{T}_{\mathrm{g}}\right)$ at a temperature around $61^{\circ} \mathrm{C}$ and a cold crystallization exothermic peak $\left(\mathrm{T}_{\mathrm{c}}=87^{\circ} \mathrm{C}\right)$ followed by a melting endothermic peak $\left(\mathrm{T}_{\mathrm{m}}=163^{\circ} \mathrm{C}\right)$ of the same entity $\left(\Delta \mathrm{H}_{\mathrm{c}}=\Delta \mathrm{H}_{\mathrm{m}}=33 \mathrm{~J} / \mathrm{g}\right)$ (figure $4(\mathrm{~B})$ ). This result indicates that the melting phenomena that follows the cold crystallization concerns only the PLLA crystal phase developed during the heating scan, thus demonstrating that completely amorphous PLLA mats were obtained through the electrospinning process, as previously reported [46]. The first heating scans of PLLA/Coll-75/25 and PLLA/Coll-50/50 samples displayed the above described PLLA thermal transitions whose entity correlated with the PLLA weight fraction in the blends. In addition, the endothermic peak of water evaporation from the Coll fraction was also visible (figure 4(B)). Since the second heating scan of the blends displayed only the thermal transitions associated to the PLLA component, it was possible to calculate the effective PLLA/Coll composition in the blends by comparing the PLLA $\Delta \mathrm{C}_{\mathrm{p}}$ and $\Delta \mathrm{H}_{\mathrm{m}}$ of the blends with those of pure PLLA. In Table 1 calorimetric data of the second heating scans are reported together with the value of PLLA content in the blend, calculated on the basis of either $\Delta \mathrm{C}_{\mathrm{p}}$ or $\Delta \mathrm{H}_{\mathrm{m}}$ :

PLLAwt $\%_{\Delta \mathrm{C}_{\mathrm{p}}}=\frac{\Delta \mathrm{C}_{\mathrm{p}}^{\mathrm{PLA} / \mathrm{Coll}}}{\Delta \mathrm{C}_{\mathrm{p}}^{\text {PLLA }}} \times 100$

PLLAwt $\%_{\Delta \mathrm{H}_{\mathrm{m}}}=\frac{\Delta \mathrm{H}_{\mathrm{m}}^{\mathrm{PLA} / \mathrm{Coll}}}{\Delta \mathrm{H}_{\mathrm{m}}^{\mathrm{PLLA}}} \times 100$

Mat composition calculated according to DSC data agrees with the starting solution composition in terms of PLLA/Coll ratio, within the accuracy of DSC quantification. 

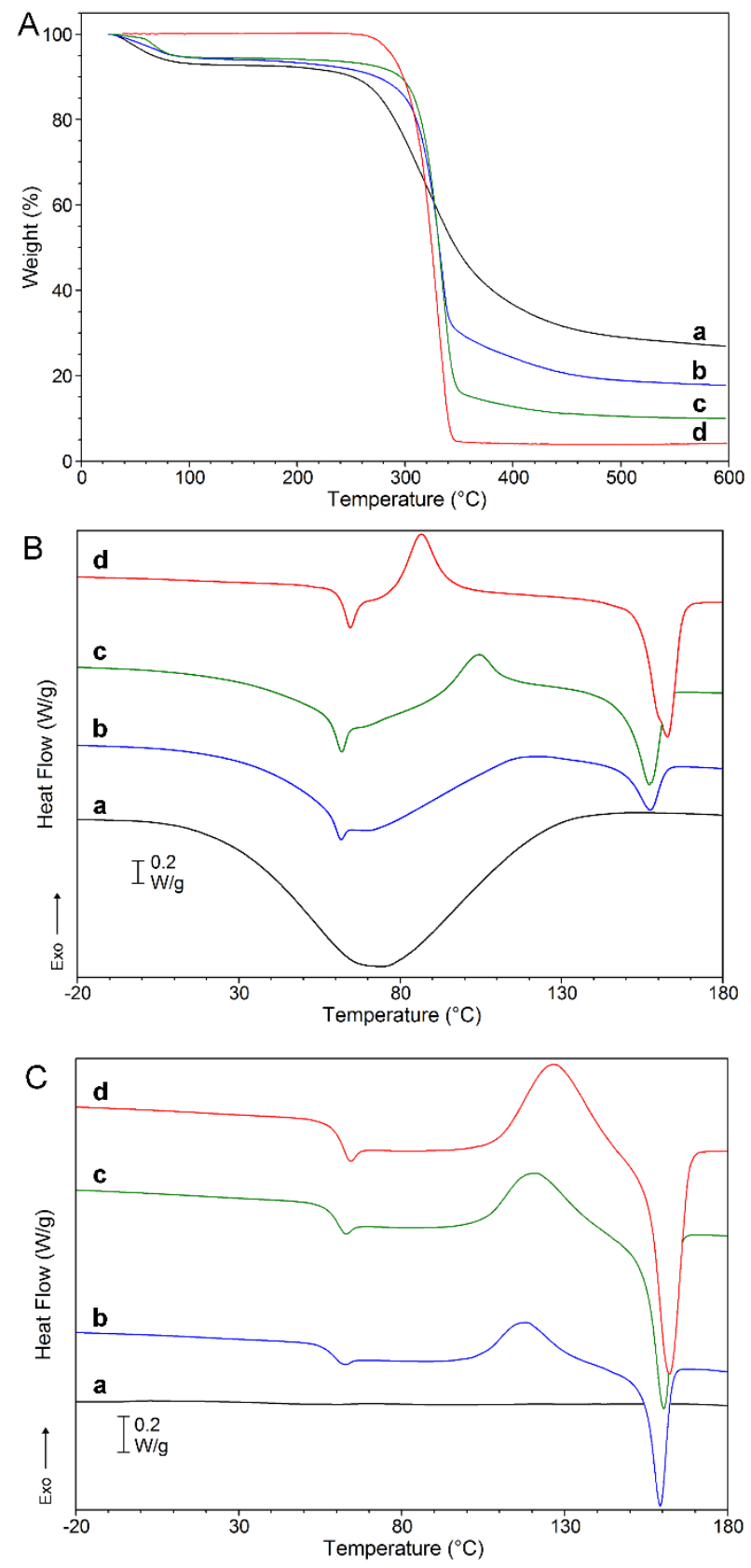

Figure 4. Thermal characterization of collagen powder (a), PLLA/Coll-50/50 (b), PLLA/Coll-75/25 (c) and PLLA (d). (A) TGA curves; (B) DSC first heating scans; (C) DSC second heating scans after controlled cooling at $10^{\circ} \mathrm{C} / \mathrm{min}$.

Table 1. Calorimetric data of Collagen, PLLA, and PLLA/Coll blends (heating run at $20{ }^{\circ} \mathrm{C} / \mathrm{min}$ following the cooling run).

\begin{tabular}{|l|c|c|c|c|c|c|c|c|}
\hline Sample & $\begin{array}{c}\boldsymbol{T}_{\boldsymbol{g}} \\
\left({ }^{\circ} \boldsymbol{C}\right)\end{array}$ & $\begin{array}{c}\Delta \boldsymbol{C}_{\boldsymbol{p}} \\
\left(\boldsymbol{J} / \mathbf{g}^{\circ} \boldsymbol{C}\right)\end{array}$ & $\begin{array}{c}\boldsymbol{T} \boldsymbol{c} \\
\left({ }^{\circ} \boldsymbol{C}\right)\end{array}$ & $\begin{array}{c}\Delta \boldsymbol{H}_{\boldsymbol{c}} \\
(\boldsymbol{J} / \boldsymbol{g})\end{array}$ & $\begin{array}{c}\boldsymbol{T}_{\boldsymbol{m}} \\
\left({ }^{\circ} \boldsymbol{C}\right)\end{array}$ & $\begin{array}{c}\Delta \boldsymbol{H}_{\boldsymbol{m}} \\
(\boldsymbol{J} / \boldsymbol{g})\end{array}$ & $\begin{array}{c}\boldsymbol{P L L A} \\
(\boldsymbol{w t} \%)^{\boldsymbol{a}}\end{array}$ & $\begin{array}{c}\boldsymbol{P L L A} \\
(\boldsymbol{w t} \boldsymbol{c})^{\boldsymbol{b}}\end{array}$ \\
\hline Collagen powder & n.a. & n.a. & n.a. & n.a. & n.a. & n.a. & & \\
\hline PLLA & 60 & 0.53 & 126 & 31 & 162 & 32 & & \\
\hline PLLA/Coll-75/25 & 59 & 0.39 & 122 & 20 & 160 & 23 & 74 & 72 \\
\hline
\end{tabular}




\begin{tabular}{|l|c|c|c|c|c|c|c|c|}
\hline PLLA/Coll-50/50 & 58 & 0.27 & 119 & 13 & 159 & 14 & 51 & 44 \\
\hline
\end{tabular}

a) PLLA $w t \%$ in the blend calculated by using Equation 3

b) PLLAwt $\%$ in the blend calculated by using Equation 4

\subsection{Release of collagen from the electrospun mats}

Figures 5(A) and 5(B) show the collagen percentage loss (Collagen Loss \%) calculated for PLLA/Coll-50/50 and PLLA/Coll-75/25. Data obtained from Biuret assay (using Equation 1) showed a significant collagen loss at the very beginning of the experiment: after $30 \mathrm{~min}$ PLLA/Coll-75/25 and PLLA/Coll-50/50 lost about 40\% and 50\% of their initial collagen content, respectively. At the end of the experiment (14 days) the collagen loss was about $50 \%$ and $70 \%$ for PLLA/Coll-75/25 and PLLA/Coll-50/50, respectively, corresponding to a final composition of PLLA/Coll-86/14 for the former, and PLLA/Coll-77/23 for the latter. Data obtained from gravimetric analysis had a similar trend but a higher collagen loss was always determined. According to gravimetric measurements (Equation 2) the collagen loss after 14 days in PBS was about $80 \%$ and $90 \%$ for PLLA/Coll-75/25 and PLLA/Coll-50/50, respectively. This discrepancy between the results of gravimetric method and Biuret assay can be explained considering that electrospun samples retrieved from the buffer were fragile and might have undergone a further loss during sample washing with fresh water.

As expected, PLLA fibers did not show any evident change of fiber morphology during 14 days of permanence on PBS (figure 5(C)). PLLA/Coll-75/25 fibers appeared slightly swollen (compare figure 5(D) with figure 3(B)) and PLLA/Coll-50/50 fibers were welded at contact points after 14 days in PBS (compare figure 5(E) with figure 3(C)).

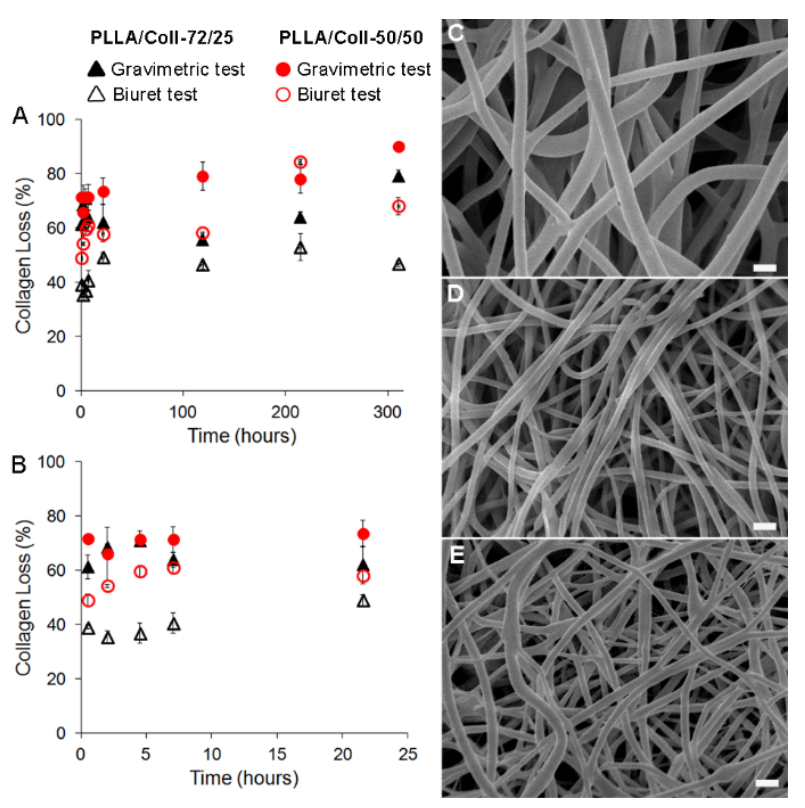


Figure 5. (A) Percentage of collagen loss during immersion of PLLA/Coll-75/25 (black triangles) and PLLA/Coll-50/50 (red circles) in PBS at different times; (B) an enlarged view in the range 0-25 hours. The collagen loss was determined both gravimetrically (full markers) and throughout Biuret assay (empty markers). Representative SEM micrographs of PLLA (C), PLLA/Coll-75/25 (D) and PLLA/Coll-50/50 (E) samples after 14 days of immersion in PBS. Scale bar $=1 \mu \mathrm{m}$.

\subsection{Mechanical properties of electrospun bundles}

Stress-strain curves of the three types of bundles (i.e. PLLA, PLLA/Coll-75/25, and PLLA/Coll50/50) presented a similar non-linear behaviour at the foot of the curve (toe region), but different trends and different magnitudes were found for the three as-spun compositions at higher stress (figure 6(A)). The PLLA bundles had a ductile behaviour, with large plastic deformation; the PLLA/Coll-75/25 bundles had a ductile behaviour, but with a higher Young modulus, higher yield and failure stress, and lower failure strain than PLLA; finally the PLLA/Coll-50/50 bundles showed an elastic and brittle behaviour, with lower Young modulus and failure stress than the other two types. Such differences were statistically significant (figure 6(B)-6(E); one-way ANOVA pvalue $<0.05)$. 

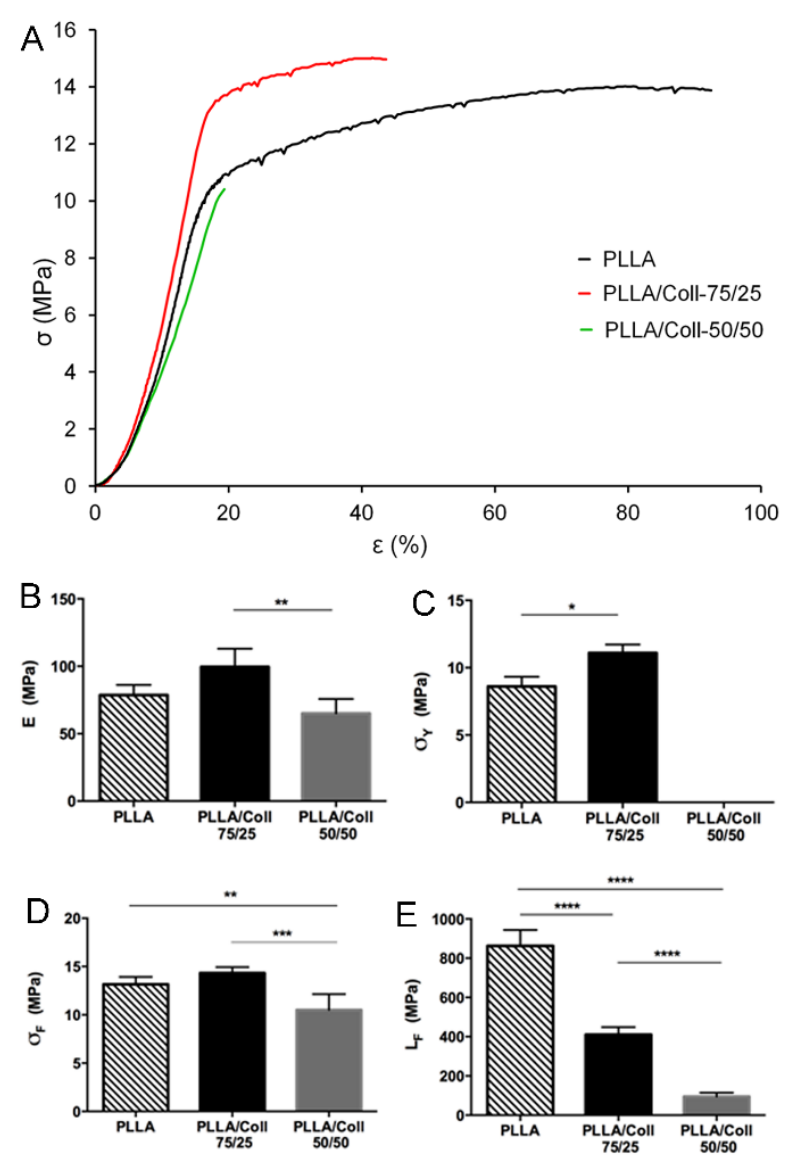

Figure 6. (A) Typical stress-strain curves for as-spun PLLA, PLLA/Coll-75/25, PLLA/Coll-50/50 bundles tested. Comparison of the mechanical properties of the as-spun bundles: (B) Young modulus $(E)$; $(C)$ yield stress $\left(\sigma_{Y}\right)$; (D) failure stress $\left(\sigma_{F}\right)$; $(E)$ work to failure $\left(L_{F}\right)$. The average and standard deviation is plotted for the three compositions, together with statistical significance of post-hoc comparisons (Tuckey multiple comparisons, * $\mathrm{P} \leq 0.05$, ** $\mathrm{P} \leq 0.01, * * * \mathrm{P} \leq 0.001$, **** $\mathrm{P} \leq$ 0.0001). The yield stress is missing for the PLLA/Coll-50/50 composition as it had a brittle behaviour.

After the electrospun bundles of the two blends (i.e. PLLA/Coll-75/25 and PLLA/Coll-50/50) were maintained in PBS they still consistently exhibited the initial non-linear toe-region, independent of the time in PBS, but showed some variation of mechanical properties over time (figure 7). In particular, the PLLA/Coll-75/25 bundles after 48 hours demonstrated a ductile behaviour and values similar to the as-spun ones (figure 7(A)). After 7 days in PBS, the bundles were still ductile, and stiffer, with lower yield and failure stress and strain. At 14 days PLLA/Coll-75/25 bundles showed an elastic-brittle behaviour, with failure stress and strain lower than the previous ones. The PLLA/Coll-50/50 bundles always showed an elastic-brittle behaviour (figure 7(B)) with values of 
stiffness that increased over time while the failure stress and strain decreased. Such differences were statistically significant (figures 7(C)-7(F); two-way ANOVA p-value $<0.05$ ).
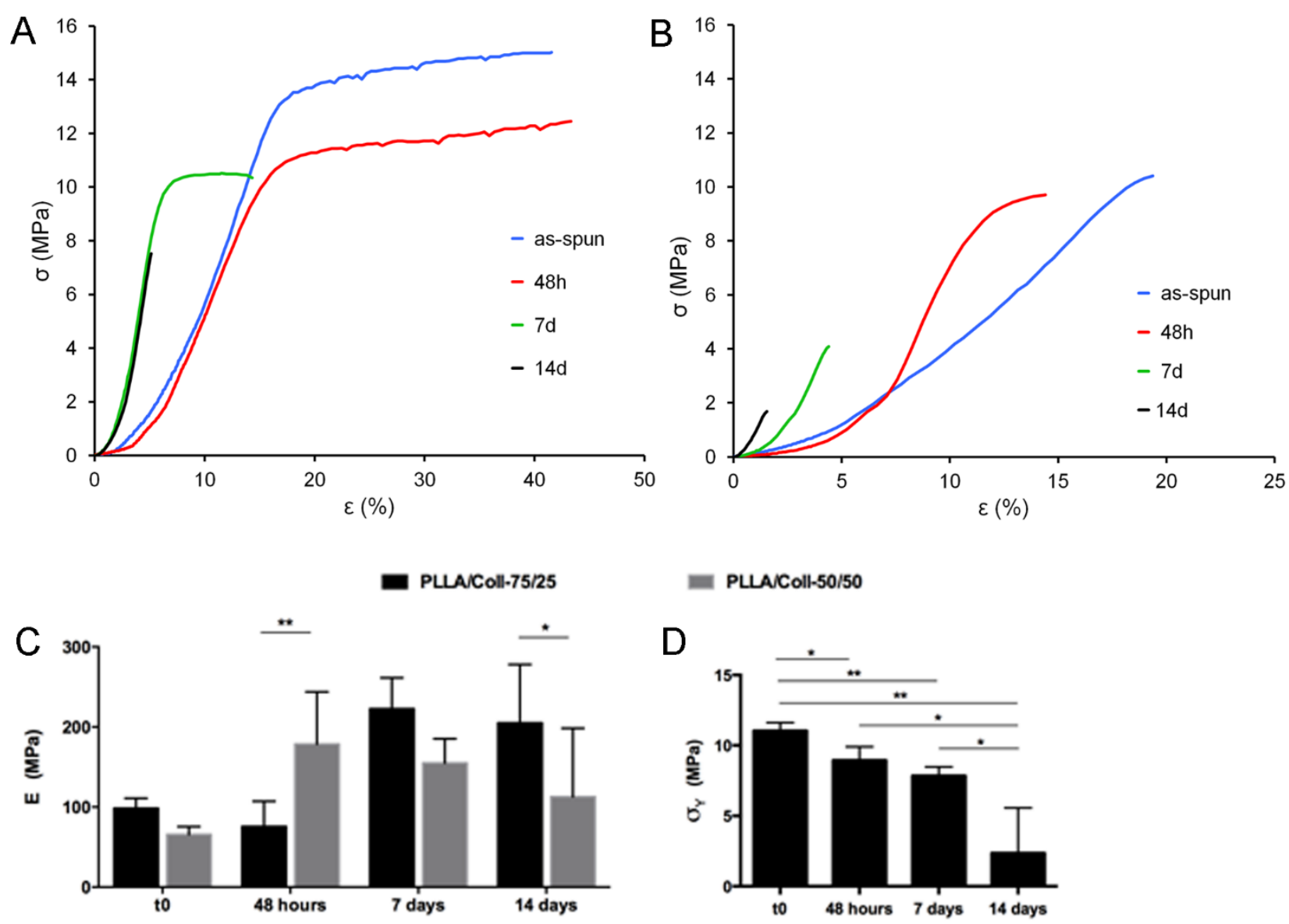

II PLACOIl-50/50
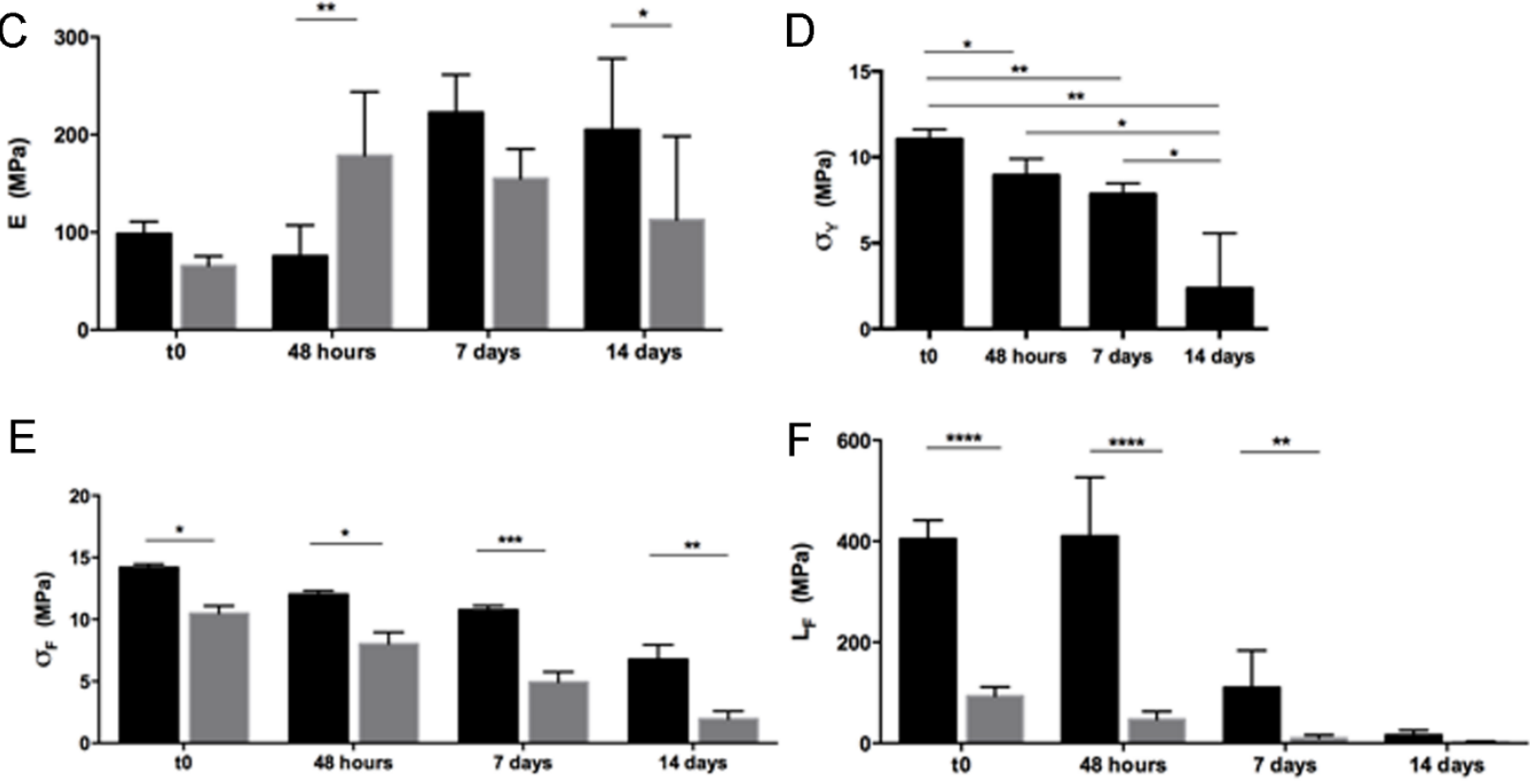

Figure 7. Typical stress-strain curves for PLLA/Coll-75/25 (A) and PLLA/Coll-50/50 (B) bundles after ageing in PBS solution (as-spun bundles (as-spun), after 48 hours (48h), 7 days (7d) and 14 days (14d) in PBS). Comparison of the mechanical properties: (C) Young modulus (E), (D) yield stress $\left(\sigma_{\mathrm{Y}}\right),(\mathrm{E})$ failure stress $\left(\sigma_{\mathrm{F}}\right),(\mathrm{F})$ work to failure $\left(\mathrm{L}_{\mathrm{F}}\right)$ of the bundles PLLA/Coll-75/25 and PLLA/Coll-50/50 as-spun and after immersion in PBS. The average and standard deviation is plotted for the three compositions, together with statistical significance of post-hoc comparisons (Tuckey multiple comparisons, * $\mathrm{P} \leq 0.05, * * \mathrm{P} \leq 0.01$, *** $\mathrm{P} \leq 0.001$, **** $\mathrm{P} \leq 0.0001$ ). The yield stress is missing for the PLLA/Coll-50/50 composition as it had a brittle behaviour. Similarly, the 
yield stress is missing for PLLA/Coll-50/50 at 14 days, as 3 specimens out of 6 had a brittle behaviour.

\subsection{Biological assessment}

First, to confirm the identity of tenocytes the immunocytochemical detection of collagen Type I and Type III, fibronectin and vimentin was performed. The majority of cells were positive for vimentin and fibronectin (figures $8(\mathrm{~A})$ and $8(\mathrm{~B})$ ). Vimentin is an intermediate filament that is characteristically found in cells of mesenchymal origin and usually used as a tenocyte marker [47, 48]. The expression of this marker was so high that counterstaining with haematoxylin and eosin was not perceptible (figure $8(\mathrm{~A})$ ). The production of collagen type I and a low expression of collagen type III were also detected (figures $8(\mathrm{C})$ and $8(\mathrm{D})$ ), indicating the fibroblastic phenotype (tenocytes) of selected population, as previously described for this model [47, 49, 50].
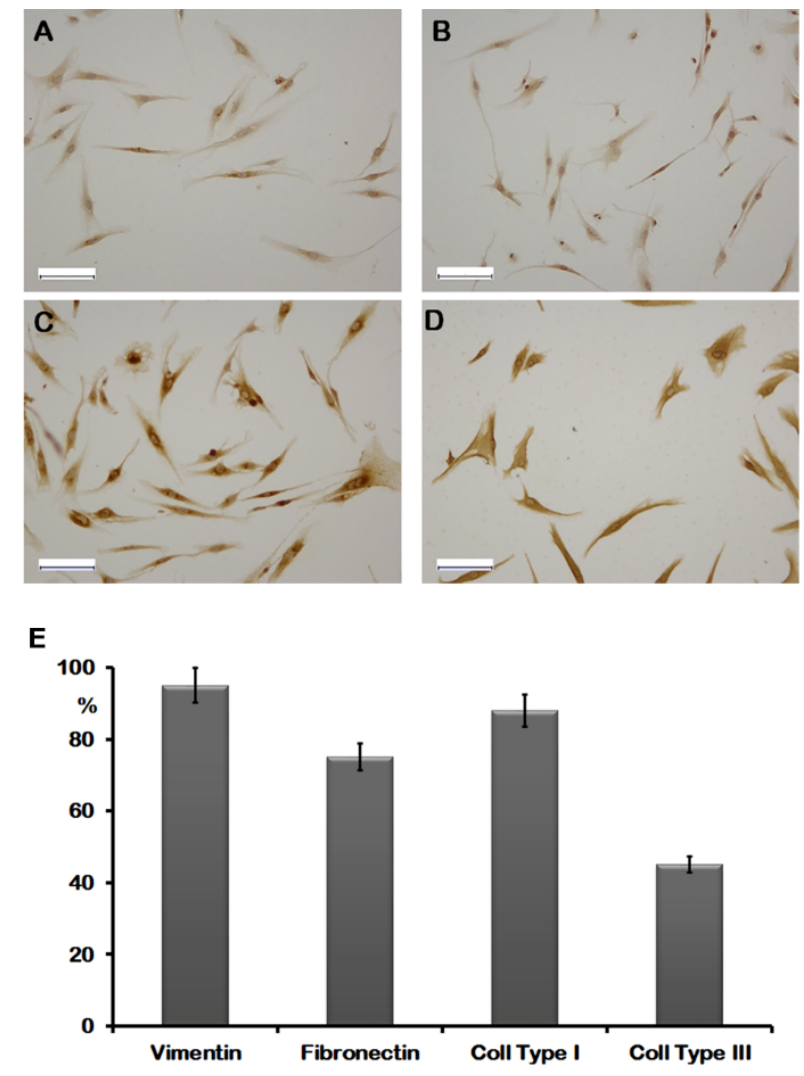

Figure 8: Tenocytes characterization. Tenocytes were characterized through vimentin (A), fibronectin (B), and Collagen Type I (C) and III (D) immunostaining. Scale bars $=50 \mu \mathrm{m}$; original magnification 200x. Histogram depicts percentage of positive cells (E).

Morphological analyses showed a different adhesion of tenocytes onto the PLLA/Coll bundles. Overall adhesion seems better on PLLA/Coll-50/50 samples in comparison to PLLA/Coll-75/25 one (figure 9). Light microscopy and SEM observations evidenced that cells were present only on 
bundle surface with a more elongated morphology on PLLA/Coll-50/50 (figures 9(B) and 9(D)) and more spread features on PLLA/Coll-75/25 at both time analysed (figure 9(F) and 9(H)).

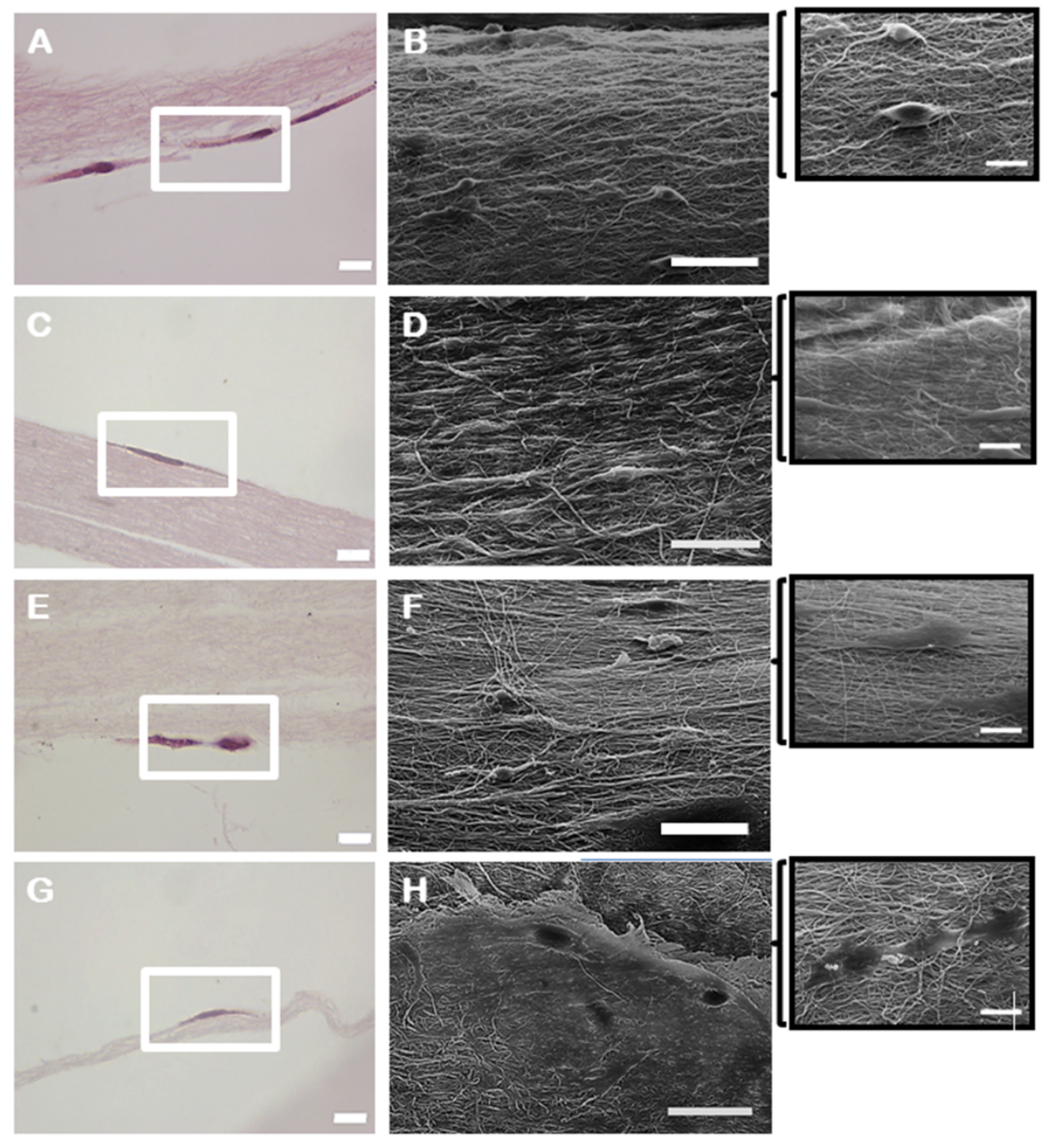

Figure 9: Light and scanning electron microscopy of tenocytes cultured onto PLLA/Coll-50/50 (AD) and PLLA/Coll-75/25 (E-H) bundles for 7 (A,B,E,F) and 14 (C,D,G,H) days. Elongated cells

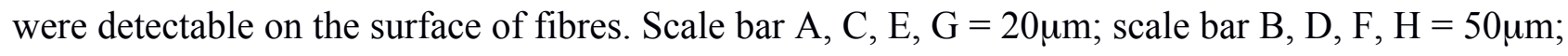
insets scale bar $=10 \mu \mathrm{m}$.

TEM ultrastructural assessment demonstrated cells in good condition. Nuclei and the relative envelops were well preserved and the quite rare mitochondria maintained a correct morphology, with well evident cristae. The Rough Endoplasmic Reticulum (RER) cisternae were always dilated and some rare vacuole autophagocytosis were visible (figure 10). This well preserved cell ultrastructure is suggestive of a good compatibility of the proposed bundles. Cells adhered to the bundles only in small points (figure 10) and not in the extended areas and this is probably responsible for the detected low proliferation. 

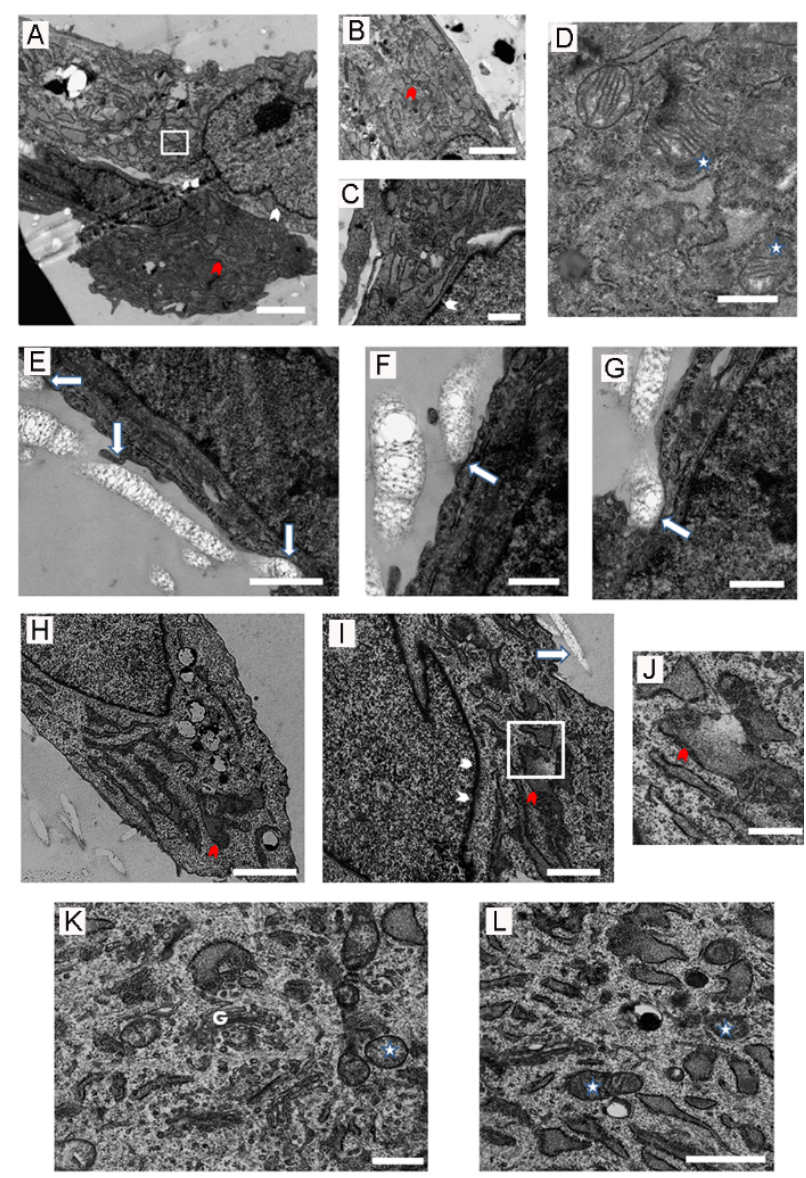

Figure 10: Transmission electron microscopy of tenocytes cultured onto PLLA/Coll-50/50 (A-G) and PLLA/Coll-75/25 (H-L) after 14 days. Cells showed a preserved cell ultrastructure as well as adhesion to bundles (E-G). Square indicates area enlarged in B and I, respectively. Note the well conserved nuclear envelop (white pointed arrows), the enlarged RER cisternae (red pointed arrows) and well conserved mitochondria (asterisks). Small bundle adhesion points are also evident (white arrows). $\mathrm{G}=$ Golgi apparatus. Scale bars $\mathrm{A}, \mathrm{B}, \mathrm{D}, \mathrm{H}=0.2 \mu \mathrm{m}$; Scale bars E, I, L = $0.1 \mu \mathrm{m}$; scale bars $\mathrm{C}, \mathrm{F}, \mathrm{G}, \mathrm{J}, \mathrm{K}=500 \mathrm{~nm}$.

\section{Discussion}

In the design of a biomimetic scaffold for tendon tissue repair it is mandatory to consider the high complexity of the natural tendon hierarchical structure both from a morphological and from a chemical point of view, in order to achieve the mechanical properties required to restore function while allowing regeneration. The aim of this study was to develop and characterize bundles of PLLA-Coll blends, to be used as bioresorbable scaffolds for the repair of tendon tissue. In this work we focused on the chemical composition, cellular response and mechanical properties. Electrospinning has been used to reproduce the morphology of a subfascicle, having a diameter in the range $300-500 \mu \mathrm{m}$, similar to that of native human Achille's tendon [51]. To manufacture the bundles, PLLA was used in combination with collagen. The expected advantages of this 
formulation were long-term degradation, plasticity and toughness (provided by PLLA) and high biocompatibility and stiffness (provided by Collagen). Two different compositions were investigated and tested against tenocytes culture: PLLA/Coll-75/25, and PLLA/Coll-50/50, while pure PLLA was characterized as a reference to assess the effect of collagen addition on scaffold properties. Collagen content in the fibers was not further increased to ensure long-term degradability of the scaffolds.

Flat mats and bundles made of sub-micrometric fibers were successfully spun (figure 1 and 2): the diameter of the fibers developed in our study (PLLA/Coll-75/25: 0.31 $\pm 0.09 \mu \mathrm{m}$; and PLLA/Coll50/50: $0.33 \pm 0.08 \mu \mathrm{m}$ ) were in the same range of the diameter of the fibrils of the Achille tendon (i.e. $0.3 \mu \mathrm{m}$ [52]). Moreover, the bundles diameters for the two blends were in the same range proposed in the literature for Achille tendon fascicles [21, 51, 53]. TGA and DSC analyses (figure 3 ) enabled to quantitatively confirm that the effective Coll content in the blend corresponded to the initial feeding, for both compositions. The wettability (measured as drop water contact angle, figure 2) indicated that increasing the collagen content led to an improved scaffold wettability, a positive aspect for the intended application. In nature, collagen molecules are arranged in a triple-helix structure $[4,21]$, which guarantees stability in a watery environment, while electrospun collagen normally requires a crosslinking treatment to reduce its dissolution upon water contact [54], However, in previous literature studies crosslinking was not performed when collagen was blended with a synthetic polymer [55-57]. In these cases, although the effective stability of electrospun fiber composition upon water contact was not verified, the addition of the natural polymer had positive effects on cell culture [55-57]. In another study it was demonstrated that collagen release from weakly crosslinked poly(lactide-co-glycolide)/collagen blends occurred and had a remarkable effect on fiber morphology at high collagen content [58]. In the present study, crosslinking was not performed in order to avoid the use of toxic agents and possible contaminants. For both PLLA/Coll compositions we found that a portion of collagen was lost after very short time of water immersion (30 minutes); the PLLA/Coll-75/25 and PLLA/Coll-50/50 scaffolds after 14 days in PBS had respectively an effective composition of 86/14 and 77/23 (determined by Biuret Assay, figure 4). These results suggest that part of collagen in our electrospun fibers is promptly dissolved by water, reasonably the portion at fiber surface, while the remaining collagen is in intimate contact with the PLLA component and is not susceptible of rapid dissolution. Similar results were found by Yang et al. on electrospun blends of PLLA/gelatin [59].

The mechanical tests confirmed that, in general, all the tested compositions showed an initial highly-compliant toe-region similar to that of natural tendon fascicles. The initial properties of the PLLA/Coll-75/25 were most promising: in fact this composition had the highest Young modulus 
(about $100 \mathrm{MPa}$ ), which was closest to the values reported for tendon collagen (about $200 \mathrm{MPa}$ [51]), and a higher failure stress than both pure PLLA and PLLA/Coll-50/50. Furthermore, PLLA/Coll-75/25 had a ductile behaviour, with higher yield stress than pure PLLA which can guarantee some safety factor in case of overload. It must be noted that the toughness of PLLA/Coll75/25 was half of that of pure PLLA. PLLA/Coll-50/50 exhibited the worst properties in terms of brittleness. The PLLA/Coll-75/25 blend showed a significant increase of the Young modulus after permanence in PBS, whereas for PLLA/Coll-50/50 the Young modulus first increased and then decreased over time. For both blends, a significant reduction of the yield stress, failure stress and work to failure was observed due to collagen loss during immersion in PBS.

The Young modulus and failure stress of our PLLA/Coll-75/25 bundles (figure 6) were in the same range as the human Achille tendon. The failure stress of fascicles from the Achille's tendon of AfroAmericans was $21.9 \pm 9.9 \mathrm{MPa}$, and for Caucasians was $28.1 \pm 9.8 \mathrm{MPa}$, with a Young's modulus of $316.8 \pm 110 \mathrm{MPa}$ and $222.8 \pm 84.6 \mathrm{MPa}$ respectively [51]. This data confirms the suitability of the Young modulus of the PLLA/Coll-75/25 bundles, especially after 7 and 14 days in PBS (about 200 $\mathrm{MPa}$, figure 7). The failure stress of PLLA/Coll-75/25 as-spun bundles is however lower than that of human tendons, and it further decreased due to permanence in PBS. A possible explanation for this progressive embrittlement and stiffening of the bundles is related to the loss of collagen from the bundles. Collagen component may be responsible of water absorption in PBS, that is expected to act as plasticizer and thus to promote material plasticity; the decrease of the amount of collagen in the fibers after 14 days in PBS may thus contribute to promoting material stiffening. This suggests that crosslinking the collagen might make it more stable after ageing in PBS. No other study reported the mechanical properties of electrospun PLLA-Coll bundles in the literature, rather mechanical properties were reported for: bundles of poly( $\varepsilon$-caprolactone) (PCL) $(\mathrm{E}=12.44 \pm 4.96$ $\mathrm{MPa}, \sigma_{\mathrm{F}}=4.12 \pm 2.00 \mathrm{MPa}$ [26]; bundles of poly(lactide-co-glicolide) $(85: 15)(\mathrm{E}=138.20 \pm 16.98$ $\mathrm{MPa}, \sigma_{\mathrm{F}}=9.48 \pm 0.82 \mathrm{MPa}$ [26]); non-woven scaffolds made of PCL/Chitosan/Cellulose nanocrystals aligned fibers $\left(\mathrm{E}=540.5 \pm 83.7 \mathrm{MPa}, \sigma_{\mathrm{F}}=39.3 \pm 1.9 \mathrm{MPa}\right)[60]$ and non-woven scaffolds made of Chitosan/PLLA/Gelatin/PEO aligned fibers $\left(\mathrm{E}=325.01 \pm 25.05 \mathrm{MPa}, \sigma_{\mathrm{F}}=\right.$ $14.23 \pm 1.08 \mathrm{MPa})[28]$.

Cells biological tests confirm that fibers orientation represents an instructive pattern for the alignment of tenocytes [50]. SEM ultrastructural analysis suggested that the presence of collagen is of outmost importance for the adhesion and proliferation of human cells. TEM investigation demonstrated, however, that tenocyte metabolic activity is not impaired by the presence of PLLA. Overall, this investigation support the hypothesis that the proposed bundles may prospectively provide a clinical option for tendon tissue augmentation. The present findings about cell viability 
are in agreement with previous works on electrospun PLLA/Coll scaffolds. Schofer et al. described the good osteoblastic differentiation of mesenchymal stem cells on random fiber electrospun scaffolds mats of PLLA/Coll in ratio 4:1 [31,32]. Theisen et al. tested the same blend in electrospun scaffolds, and demonstrated a good proliferation of human tenoblasts from long biceps tendons [33]. Conçalves et al. studied the morphology, mechanical properties and osteoblastic differentiation of random electrospun fiber scaffolds mats made by five different kinds of PLLA/Coll blends and solvents systems, confirming their good biocompatibility [34].

One limitation of the present findings is certainly the fast loss of collagen, which resulted in a significant loss of the mechanical properties of the two blends within 14 days in PBS that can be reasonably limited by treating the electrospun bundles to crosslink the collagen.

It is pointed out that after permanence in PBS, some of the bundles had shrunk to the point that their length was no more sufficient to roll them around the pins of the capstan grips for the tensile tests. In these cases, standard clamps were used: this might have resulted in a slight under-estimate of the failure properties. However, as no specimen failed in the clamp, such effects, if present at all, must have been negligible. Hansen et al. used an actuator speed of $2 \mathrm{~mm} / \mathrm{min}$, with a specimen free length of $10 \mathrm{~mm}$ [48], which results in a strain rate slightly lower than the present study.

It must be noted that our bundles were produced with an operator-dependent approach. In the future, a more automated electrospinning configuration should be defined to standardize the manufacturing process. In fact, it has been shown that bundle production can be standardized [22].

From a biological point of view, it will be necessary to improve cell adhesion on the proposed bundles by limiting the loss of collagen and possibly tests other kind of cells involved in tendon regeneration (i.e. mesenchymal stem cells).

\section{Conclusions}

This study has demonstrated the feasibility of manufacturing bundles of a blend of bioresorbable polymers (PLLA and collagen). The use of electrospinning resulted in an arrangement of the fibers that mimicked that of tendon collagen. In fact, bundles with a cross section of 300-500 micron and a length of $150 \mathrm{~mm}$ were fabricated with different blends. The mechanical properties (stiffness and strength) achieved are similar to those of natural tendon. The cellular culture tests confirmed that the electrospun bundles of the selected blends promoted tenocyte adhesion and proliferation. In this study single bundles were manufactured and tested. The future steps will include assembling multiple bundles in a multiscale arrangement mimicking the hierarchical structure of collagen in the human tendon. 


\section{Acknowledgements}

FP7 COST Action MP1206 "Electrospun Nano-fibres for bio inspired composite materials and innovative industrial applications" and the Italian Ministry of University and Research (MIUR) is acknowledged. Type I collagen was kindly provided by Kensey Nash Corporation d/b/a DSM Biomedical (Exton, USA).

\section{References}

[1] Abbah S A, Spanoudes K, O'Brien T, Pandit A and Zeugolis D I 2014 Assessment of stem cell carriers for tendon tissue engineering in pre-clinical models Stem Cell Research \& Therapy 5 1-9

[2] Dy C J, Daluiski A, Do H T, Hernandez-Soria A, Marx R and Lyman S 2012 The Epidemiology of Reoperation After Flexor Tendon Repair The Journal of Hand Surgery 37 919-924

[3] Soroceanu A, Sidhwa F, Aarabi S, Kaufman A and Glazebrook M 2012 Surgical Versus Nonsurgical Treatment of Acute Achilles Tendon Rupture: A Meta-Analysis of Randomized Trials The Journal of Bone \& Joint Surgery 94 2136-2143

[4] Lomas A J, Ryan C N M, Sorushanova A, Shologu N, Sideri A I, Tsioli V, Fthenakis G C, Tzora A, Skoufos I, Quinlan L R, O'Laighin G, Mullen A M, Kelly J L, Kearns S, Biggs M, Pandit A and Zeugolis D I 2015 The past, present and future in scaffold-based tendon treatments Advanced Drug Delivery Reviews 84 257-277

[5] Sharma P, Maffulli N 2005 Tendon Injury and Tendinopathy: Healing and Repair The Journal of Bone \& Joint Surgery 87 187-202

[6] Wang J H C 2006 Mechanobiology of tendon Journal of Biomechanics 39 1563-1582

[7] Woo S L, Gomez M A, Woo Y K and Akeson W H 1982 Mechanical properties of tendons and ligaments. II. The relationships of immobilization and exercise on tissue remodeling Biorheology 19 397-408

[8] Miller D, Waterston R J, Barrass V and Muffulli N 2005 Conservative management, percutaneous or open repair of acute Achilles tendon rupture: a retrospective study Scottish Medical Journal 50 160-165

[9] Bagnaninchi P O, Yang Y, El Haj A J and Maffulli N 2007 Tissue engineering for tendon repair British Journal of Sports Medicine 41 e10-

[10] Ichioka S, Harii K, Yamada A and Sugiura Y 1994 Tendinocutaneous free flap transfer to cover an extensive skin-tendon defect of the dorsum of the hand: case report Journal of Trauma-Injury Infection \& Critical Care 36 901-903

[11] Wang S, Zinderman C, Wise R and Braun M 2007 Infections and human tissue transplants: review of FDA MedWatch reports 2001-2004 Cell and Tissue Banking 8 211-219

[12] Adani R, Marcoccio I and Tarallo L 2003 Flap coverage of dorsum of hand associated with extensor tendons injuries: A completely vascularized single-stage reconstruction Microsurgery 23 32-39

[13] Kim S W, Hong J P, Lee W J, Chung Y K and Tark K C 2003 Single-Stage Achilles Tendon Reconstruction Using a Composite Sensate Free Flap of Dorsalis Pedis and Tendon Strips of the Extensor Digitorum Longus in a Complex Wound Annals of Plastic Surgery 50 653-657

[14] McGuire D A, Hendricks S D 2007 Allografts in Sports Medicine Operative Techniques in Sports Medicine 15 46-52

[15] K.Hampson, N.R.Forsyth, A.El Haj, N.Maffulli, in Topics in Tissue Engineering, vol. 4, 2008, Ch. 3. 
[16] C.Kim, R.Pedowitz, in Daniel's Knee Injuires: Ligament and Cartilage Structure, Function, Injury, and Repair (Eds: R.Pedowitz, J.O'Conner, W.Kakeson), Lippincott Williams \& Wilkins, Philadelphia, 2007.

[17] de Vos R J, Weir A and van Schie H M 2010 Platelet-rich plasma injection for chronic achilles tendinopathy: A randomized controlled trial JAMA 303 144-149

[18] Schepull T, Kvist J, Norrman H, Trinks M, Berlin G and Aspenberg P 2011 Autologous Platelets Have No Effect on the Healing of Human Achilles Tendon Ruptures: A

Randomized Single-Blind Study The American Journal of Sports Medicine 39 38-47

[19] Bowman K F, Muller B, Middleton K, Fink C, Harner C D and Fu F H 2013 Progression of patellar tendinitis following treatment with platelet-rich plasma: case reports Knee Surgery, Sports Traumatology, Arthroscopy 21 2035-2039

[20] Kannus P 2000 Structure of the tendon connective tissue Scandinavian Journal of Medicine \& Science in Sports $10312-320$

[21] Goh K L, Listrat A and Béchet D 2014 Hierarchical Mechanics of Connective Tissues: Integrating Insghts from Nano to Macroscopic Studies Journal of Biomedical Nanotechnology 10 2464-2507

[22] U.Ali, Y.Zhou, X.Wang, T.Lin, in Nanofibers- Production, Properties \& Functional Applications (Ed: T.Lin), InTech, 2011, Ch. 8.

[23] Mouthuy P-A, Zargar N, Hakimi O, Lostis E and Carr A 2015 Fabrication of continuous electrospun filaments with potential for use as medical fibres Biofabrication 7025006

[24] Sun B, Jiang X J, Zhang S, Zhang J C, Li Y F, You Q Z and Long Y Z 2015 Electrospun anisotropic architectures and porous structures for tissue engineering Journal of Materials Chemistry B 3 5389-5410

[25] Bosworth L A, Rathbone S R, Bradley R S and Cartmell S H 2014 Dynamic loading of electrospun yarns guides mesenchymal stem cells towards a tendon lineage Journal of the Mechanical Behavior of Biomedical Materials 39 175-183

[26] Bosworth L A 2014 Travelling along the Clinical Roadmap: Developing Electrospun Scaffolds for Tendon Repair Conference Papers in Science 2014304974

[27] Bosworth L A, Alam N, Wong J K and Downes S 2013 Investigation of 2D and 3D electrospun scaffolds intended for tendon repair Journal of Materials Science: Materials in Medicine 24 1605-1614

[28] Zhang C, Yuan H, Liu H, Chen X, Lu P, Zhu T, Yang L, Yin Z, Heng B C, Zhang Y and Ouyang H 2015 Well-aligned chitosan-based ultrafine fibers committed teno-lineage differentiation of human induced pluripotent stem cells for Achilles tendon regeneration Biomaterials $\mathbf{5 3} 716-730$

[29] Xu Y, Wu J, Wang H, Li H, Di N, Song L, Li S, Li D, Xiang Y, Liu W, Mo X and Zhou Q 2013 Fabrication of Electrospun Poly(L-Lactide-co-e-Caprolactone)/Collagen Nanoyarn Network as a Novel, Three-Dimensional, Macroporous, Aligned Scaffold for Tendon Tissue Engineering Tissue Engineering. Part C, Methods 19 925-936

[30] Yang C, Deng G, Chen W, Ye X and Mo X 2014 A novel electrospun-aligned nanoyarnreinforced nanofibrous scaffold for tendon tissue engineering Colloids and Surfaces B:

Biointerfaces 122 270-276

[31] Schofer M D, Boudriot U, Leifeld I, Sutterlin R I, Rudisile M, Wendorff J H, Greiner A, Paletta J R J and Fuchs-Winkelmann S 2009 Characterization of a PLLA-collagen I blend nanofiber scaffold with respect to growth and osteogenic differentiation of human mesenchymal stem cells ScientificWorldJournal 9 118-129

[32] Schofer M D, Veltum A, Theisen C, Chen F, Agarwal S, Fuchs-Winkelmann S and Paletta J R J 2011 Functionalisation of PLLA nanofiber scaffolds using a possible cooperative effect between collagen type I and BMP-2: impact on growth and osteogenic differentiation of human mesenchymal stem cells Journal of Materials Science: Materials in Medicine 22 1753-1762 
[33] Theisen C, Fuchs-Winkelmann S, Knappstein K, Efe T, Schmitt J, Paletta J R and Schofer M D 2010 Influence of nanofibers on growth and gene expression of human tendon derived fibroblast BioMedical Engineering OnLine 9 1-12

[34] Gonçalves F, Bentini R, Burrows C M, Carreira C A, Kossugue M P, Sogayar C M and Catalani H L 2015 Hybrid Membranes of PLLA/Collagen for Bone Tissue Engineering: A Comparative Study of Scaffold Production Techniques for Optimal Mechanical Properties and Osteoinduction Ability Materials 8 408-423

[35] Saino E, Focarete M L, Gualandi C, Emanuele E, Cornaglia A I, Imbriani M and Visai L 2011 Effect of Electrospun Fiber Diameter and Alignment on Macrophage Activation and Secretion of Proinflammatory Cytokines and Chemokines Biomacromolecules 12 19001911

[36] Gazzano M, Gualandi C, Zucchelli A, Sui T, Korsunsky A M, Reinhard C and Focarete M L 2015 Structure-morphology correlation in electrospun fibers of semicrystalline polymers by simultaneous synchrotron SAXS-WAXD Polymer 63 154-163

[37] Liu Z Q 1991 Scale space approach to directional analysis of images Applied Optics 30 1369-1373

[38] Schindelin J, Arganda-Carreras I, Frise E, Kaynig V, Longair M, Pietzsch T, Preibisch S, Rueden C, Saalfeld S, Schmid B, Tinevez J Y, White D J, Hartenstein V, Eliceiri K, Tomancak P and Cardona A 2012 Fiji: an open-source platform for biological-image analysis Nature Methods 9 676-682

[39] Schneider C A, Rasband W S and Eliceiri K W 2012 NIH Image to ImageJ: 25 years of image analysis Nature Methods 9 671-675

[40] Janairo G, Linley Sy M, Yap L, LIanos-Lazaro N and Robles J 2011 Determination of the Sensivity Range of Biuret Test for Undergraduate Biochemestry Experiments e-Journal of Science \& Technology 6 77-83

[41] Colombo V, Fabiani D, Focarete M L, Gherardi M, Gualandi C, Laurita R and Zaccaria M 2014 Atmospheric Pressure Non-Equilibrium Plasma Treatment to Improve the Electrospinnability of Poly(L-Lactic Acid) Polymeric Solution Plasma Processes and Polymers 11 247-255

[42] Torricelli P, Gioffrè M, Fiorani A, Panzavolta S, Gualandi C, Fini M, Focarete M L and Bigi A 2014 Co-electrospun gelatin-poly(l-lactic acid) scaffolds: Modulation of mechanical properties and chondrocyte response as a function of composition Materials Science and Engineering: C 36 130-138

[43] Gualandi C, Govoni M, Foroni L, Valente S, Bianchi M, Giordano E, Pasquinelli G, Biscarini F and Focarete M L 2012 Ethanol disinfection affects physical properties and cell response of electrospun poly(l-lactic acid) scaffolds European Polymer Journal 482008 2018

[44] Puett D 1967 DTA and heals of hydration of some polypeptides Biopolymers 5 327-330

[45] Lim J J, Shamos M H 1974 Evaluation of kinetic parameters of thermal decomposition of native collagen by thermogravimetric analysis Biopolymers 13 1791-1807

[46] Mukherjee S, Gualandi C, Focarete M L, Ravichandran R, Venugopal J R, Raghunath M and Ramakrishna S 2011 Elastomeric electrospun scaffolds of poly(l-lactide-co-trimethylene carbonate) for myocardial tissue engineering Journal of Materials Science: Materials in Medicine 22 1689-1699

[47] Fong G, Backman L J, Andersson G, Scott A and Danielson P 2013 Human tenocytes are stimulated to proliferate by acetylcholine through an EGFR signalling pathway Cell and Tissue Research 351 465-475

[48] Giusti I, D'Ascenzo S, Mancò A, Di Stefano G, Di Francesco M, Rughetti A, Dal Mas A, Properzi G, Clvisi V and Dolo V 2014 Platelet concentration in platelet-rich plasma affects tenocytes behaviour in vitro BioMed Research International 2014630870 
[49] Backman L J, Fong G, Andersson G, Scott A and Danielson P 2011 Substance P Is a Mechanoresponsive, Autocrine Regulator of Human Tenocyte Proliferation PLoS One 6 e27209

[50] Gigante A, Cesari E, Busilacchi A, Manzotti S, Kyriakidou K, Greco F, Primio R D and Mattioli-Belmonte M 2009 Collagen I membranes for tendon repair: Effect of collagen fiber orientation on cell behavior Journal of Orthopaedic Research 27 826-832

[51] Hansen P, Aagaard P and Magnusson S P 2012 Biomechanical properties of isolated fascicles of the Iliopsoas and Achilles tendons in African American and Caucasian men Annals of anatomy 194 457-460

[52] Pingel J, Lu Y, Starborg T, Fredberg U, Langberg H, Nedergaard A, Weis M, Eyre D, Kjaer $\mathrm{M}$ and Kadler K E 2014 3-D ultrastructure and collagen composition of healthy and overloaded human tendon: evidence of tenocyte and matrix buckling Journal of Anatomy 224 548-555

[53] Hansen P, Kovanen V, Holmich P, Krogsgaard M, Hansson P, Dahl M, Hald M, Aagaard P, Kjaer M and Magnusson S P 2013 Micromechanical Properties and Collagen Composition of Ruptured Human Achilles Tendon The American Journal of Sports Medicine 41 437-443

[54] Fiorani A, Gualandi C, Panseri S, Montesi M, Marcacci M, Focarete M L and Bigi A 2014 Comparative performance of collagen nanofibers electrospun from different solvents and stabilized by different crosslinkers Journal of Materials Science: Materials in Medicine 25 2313-2321

[55] Xue J, Shi R, Niu Y, Gong M, Coates P, Crawford A, Chen D, Tian W and Zhang L 2015 Fabrication of drug-loaded anti-infective guided tissue regeneration membrane with adjustable biodegradation property Colloids and Surfaces B: Biointerfaces 135 846-854

[56] Kijenska E, Prabhakaran M P, Swieszkowski W, Kurzydlowski K J and Ramakrishna S 2012 Electrospun bio-composite P(LLA-CL)/collagen I/collagen III scaffolds for nerve tissue engineering Journal of Biomedical Materials Research Part B: Applied Biomaterials 100B 1093-1102

[57] Li M, Mondrinos M J, Chen X, Gandhi M R, Ko F K and Lelkes P I 2006 Co-electrospun poly(lactide-co-glycolide), gelatin, and elastin blends for tissue engineering scaffolds Journal of Biomedical Materials Research Part A 79A 963-973

[58] Jose M V, Thomas V, Dean D R and Nyairo E 2009 Fabrication and characterization of aligned nanofibrous PLGA/Collagen blends as bone tissue scaffolds Polymer 50 3778-3785

[59] Yang X, Xu Q, Yan N, Sui G, Cai Q and Deng X 2011 Structure and wettability relationship of coelectrospun poly (L-lactic acid)/gelatin composite fibrous mats Polymers for Advanced Technologies 22 2222-2230

[60] Domingues R M A, Chiera S, Gershovich P, Motta A, Reis R L and Gomes M E 2016 Enhancing the Biomechanical Performance of Anisotropic Nanofibrous Scaffolds in Tendon Tissue Engineering: Reinforcement with Cellulose Nanocrystals Advanced Healthcare Materials 5 1364-1375 